\title{
An investigation into EFL teachers' motivation to teach from a self-determination perspective
}

\author{
Roohani, Ali $\bowtie$ \\ Shahrekord University, Iran (roohani.ali@gmail.com) \\ Hashemian, Mahmood \\ Shahrekord University, Iran (m72h@hotmail.com) \\ Dayeri, Khadijeh \\ Shahrekord University, Iran (Kh.dayeri@yahoo.com)
}

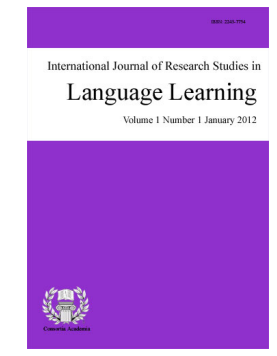

ISSN: 2243-7754 Online ISSN: 2243-7762

OPEN ACCESS

\section{Abstract}

Teacher motivation has recently received a lot of attention in different educational areas. However, little attempt has been made to explore the role of motivation in English as a Foreign Language (EFL) teachers in Iran from self-determination perspective. Feeling this gap, the present study employed a mixed method approach to identify the motivational profiles among Iranian EFL teachers and explore the relationships between their motivational profiles and their demographic variables. To these ends, the cluster analysis was used to identify the motivational profiles in a sample of 115 Iranian EFL teachers. The participants, who were selected through non-probability sampling, were asked to fill out the Motivation to Teach Questionnaire (MTQ) as well as demographic information questionnaire. A three-cluster solution resulted in three distinctive motivational profiles: Low, Moderate, and High groups. Additionally, results from Chi-square tests revealed that there were significant associations between cluster membership and demographic variables such as years of experience and place of work. Follow-up semi-structured interviews illustrated the underlying sources of the Iranian EFL teachers' types of motivation within each cluster. Findings have implications for EFL teachers and educational policy makers to take into account teachers' motivational types and attributes to foster teacher development, and consequently, promote EFL learning.

Keywords: EFL teachers; self-determination theory; motivational profiles; autonomous motivation; demographic variable 


\section{An investigation into EFL teachers' motivation to teach from a self-determination perspective}

\section{Introduction}

Teacher quality has been identified as having an undeniable role in students' academic achievements (Dörnyei \& Ushioda, 2011). Language teachers are considered as one of the primary sources for language input and play the role of facilitators in language learning process (Sanders, 2000). This role has become more crucial in the present complex educational climate with rapid developmental growth, and adds importance to the understanding of the factors influencing EFL teachers' success and development. These factors include psychological, social, and work-related demands and expectations which might affect teachers' effectiveness and progress (Dörnyei \& Ushioda, 2011). Although a great deal of attention has been put into the issues of teacher education, (e.g., Nieto, 2005; Richardson \& Watt, 2005; Watt \& Richardson, 2011), EFL teachers seem to be overlooked in this respect.

Among psychological factors, motivation is one of the most significant contributors to high-level performance in teaching endeavor. The importance of teacher motivation can be highlighted by Dörnyei and Ushioda (2011) when they describe it as a multifaceted construct which has a great potential impact on teachers' behavior; it is a psychological process underlying teachers' choices, efforts, and persistence. They posit that the teachers' true zeal and dedication for teaching is one of the most important factors which can affect learners' motivation to learn, and if a teacher is motivated to teach, he or she has the possibility to affect their students' motivation to learn. Given the fact that teachers deal with different personal- and job-related issues which make them leave the jobs worldwide, and the need for quality teaching, it becomes imperative to understand what factors motivate teachers to still remain in the profession.

Different theoretical foundations have approached and conceptualized motivation, among which self-determination theory (SDT) can be particularly useful (Deci \& Ryan, 1985; Deci \& Ryan, 2000). This theory proposes that individuals may have different reasons to engage in their jobs, and these various motivational factors can impact on their behaviors and emotions. Different groups of teachers might be identified by different motivational profiles. For instance, one type of motivation might be prominent for a group of teachers while marginal for some other teachers. Others might have a combination of different motives because they need to meet external demands and at the same time they find teaching enjoyable, as well. As suggested by SDT (Deci \& Ryan, 2000), these various reasons or motivational regulations have a differential impact on teachers' functioning; thus, it would be fruitful to explore the EFL teachers' motivation within the conceptual model of SDT. Three types of motivation have been identified by motivation theories: intrinsic motivation, extrinsic motivation, and amotivation. Individuals with intrinsic motivation display a behavior for its own sake and for the joy of activity. However, extrinsic motivation deals with performing a behavior with the aim of achieving a reward or avoiding the punishment. Amotivation, is defined as the lack of any motivation (Deci \& Ryan, 2000; Dörnyei \& Ushioda, 2011).

The intrinsic dimension of teacher motivation is related to the inherent desire of doing a purposeful activity related to one's subject area of interest, in an autonomous manner in their teaching community, with self-efficacy and instructional goal (Deci \& Ryan, 2000). The body of literature reveals that teachers who are self-determined, that is, intrinsically motivated in their teaching are more likely to support students' autonomy, and this in turn leads to greater intrinsic motivation among students (Pelletier, Seguin-Levesque, \& Legault, 2002; Reeve, Bolt, \& Cai, 1999). Therefore, motivation, specifically intrinsic motivation may be viewed as a precious treasure among teachers, as it is associated with several desirable academic achievements (Deci \& Ryan, 1985; Hidi \& Harackiewicz, 2000; Poonam, 1997). Although conventional views of motivation (i.e., Deci, 1971; Weiner, 1985) assume that intrinsic and extrinsic motivations are not just separate processes but also incompatible, SDT 
An investigation into EFL teachers' motivation to teach from a self-determination perspective

postulates that there can be a continuum of extrinsic motivations indicating various degrees of their external control or internal regulations which may accompany intrinsic motivation. Thus, they conclude that there is not necessarily an intrinsic/extrinsic dichotomy.

Deci and Rayn (2000) describe the extrinsic motivation continuum as comprising four forms of motivation varying in their degree: Integrated regulation refers to individuals functioning to meet basic psychological needs that are consistent with a true sense of self. Identified regulation is characterized as individuals acting to achieve personally valued goals. Introjected regulation comprises the behaviors performed to avoid punishment or gain pride and being without a full sense of self-esteem. In external regulation, individuals engage in activities for external reasons such as rewards or benefits. Based on SDT, teachers can be autonomously motivated (enjoying teaching or valuing its importance) or controlled (feeling externally or internally pressured) (Deci \& Ryan, 2000). While integrated and identified regulations represent autonomous forms of motivation because they refer to behaviors performed by choice, introjected and external regulations are viewed as controlled forms of motivation because they exist in situations where individuals are hindered to feel autonomous and to have choices (Deci \& Ryan; 2000).

In light of this awareness, it is important to scrutinize the nature of motivation in the second/foreign language (L2) teaching and learning areas of education and research (Dörnyei \& Ushioda, 2011). The motivation as one of the most important psychological factors can have its manifestation on EFL teachers functioning and language teaching and learning achievements (Dörnyei \& Ushioda, 2011). Thus, identifying and understanding the EFL teachers' motivations to teach and the associated underlying roles of social and work-related factors seem to be crucial for the EFL educational activities in Iran. Moreover, demographic variables can be one of those factors which may influence teachers' level of commitment and effectiveness.

Whereas the SDT theory has been successfully applied to a wide variety of contexts, including education (Deci, Vallerand, Pelletier, \& Ryan, 1991), there is scarcity in the body of literature regarding EFL teachers' motivation from SDT perspective. Furthermore, the relation of demographic characteristics of EFL teachers to their types of motivation has remained unclear; hence, the present study is a response to the need for investigating the motivations of EFL teachers and their contribution to their demographic characteristics with an eye on SDT in the context of Iran.

\section{Review of literature}

Although motivation for teaching was left unnoticed in education research for a long time, researchers have now turned their attention to the topic, and teacher motivation has become the center of an extensive research in different fields of study specially the field of physical education. Some studies have investigated the effects of teacher motivation on students' motivation and outcomes, and others have explored the contributions of different personal and organizational factors to teachers' motivation for teaching. For instance, in a cross-sectional study, Bieg, Backes, and Mittag (2011), examined the role of teachers' motivation for teaching, teachers' care, and autonomy support in students' motivation. Different questionnaires were administered to students and teachers. The findings from hierarchical linear modeling indicated students' individual perceptions of teachers' autonomy support, and teachers' care predicted students' intrinsic motivation. Perceived autonomy support by the teacher on class level proved to be another predictor. On the other hand, intrinsic motivation for teaching in addition to teachers' reported autonomy support and care had no impact on students' intrinsic motivation.

Another study is a work done by Thomson, Turner, and Nietfeld (2012) who utilized cluster analysis to identify typologies of prospective teachers enrolled in a teacher education program in the U.S. based on their self-report motivation for teaching. Three distinctive typologies were generated and the differences among them were investigated in relation to participants' beliefs about teaching. Carrying out two studies, Gillet, Berjot, Vallerand, Amoura, and Rosnet (2012) also adopted a person-centered approach to identify motivational profiles in fencers and long-distance running athletes. Cluster analyses revealed three motivational profiles: Low, 
Moderate, and High groups. In both studies, results also indicated that athletes characterized by the High motivational profile obtained the highest levels of performance.

In the educational settings, few studies can be found examining individuals' motivations to teach English as their career. As an example, we can mention the work of Griva, Panitsidou, and Chostelidou (2012) who attempted to identify factors related to motivation and professional satisfaction of EFL teachers working in the Greek education system. Conducting a mixed method investigation, they designed a model to link the job satisfaction to EFL teaching motivations. They concluded that their integrative model could provide for a reference framework to guiding policy reforms and interventions, and to developing effective quality assurance systems with regard to foreign language teaching.

In his qualitative study, Kumazawa (2013) examined the teaching motivations of four novice secondary school EFL teachers in Japan. The data collection was undertaken by an in-depth interview. The collected data were then analyzed in the framework of narrative inquiry. His study based on possible selves theory revealed that their motivations were negatively affected by the conflicts between their different possible selves. He concluded that for novice teachers like the participants in his study, too large gaps between their initial ideal selves, ought-to selves, and actual selves could lead to reduced effects of their future self-images as a source of motivation.

While research has widely addressed teacher motivation and its effects in different educational settings, the scarcity of research exploring the development of motivational characteristics specific to EFL teachers is still felt. To the best of present researchers' knowledge, no previous studies have attempted to examine EFL teachers' motivation to teach through a person-centered approach and from a SDT perspective. Filling this gap, the present study aimed to add to this literature by examining EFL teachers' motivational profiles and their relation with demographic characteristics. In line with the above mentioned objectives, the present study was an attempt to provide answers to the following questions:

$>\quad$ What are the major types of EFL teachers' motivation for teaching?

$>$ Are there any significant differences among the emerged motivational profiles (clusters) of the Iranian EFL teachers?

$>$ Are there any relationships between EFL teachers' motivational profiles and their demographic variables?

$>$ How are different combined motivations to teach described by each cluster?

\section{Method}

\subsection{Quantitative phase}

The quantitative section of this study sought to identify the Iranian EFL teachers' types of motivation using both variable- and person-centered approach, and to examine the relation between demographic variables and the participants' types of motivations.

Participants - Participants were 115 EFL teachers (35 males and 80 females) from two southwest provinces in Iran. Their age ranged from 21 to 45 teaching in various private institutes and public schools with different years of experience from five to 25 years. The majority of the teachers held the bachelor's degree (about $62 \%$ ), and the rest held the master's degree (about 34\%), and $\mathrm{PhD}$ degree (about 4\%).

Instruments - The Motivation to Teach Questionnaire (MTQ; Soenens, Sierens, Vansteenkiste, Dochy, Goossens, 2012) was used to measure EFL teachers' motivation to teach. The MTQ contained a total of 16 items representing four subscales including intrinsic motivation, identified, introjected, and external regulations. 
An investigation into EFL teachers' motivation to teach from a self-determination perspective

Participants responded to items based on a five-point Likert scale ranging from 1 (completely disagree) to 5 (completely agree). The validity and reliability of the MTQ have already been confirmed by the researchers (Soenens et al., 2012).

The participants were also asked to answer the questions related to their demographic information. The questions required information about their gender, age, educational degree, years of experience, place of work, and employment status.

\subsection{Qualitative phase}

The qualitative data were collected in the second phase of the study in order to gain further understanding of the underlying factors and sources of the participants' motivations (autonomous vs. controlled) to teach within each cluster. In this phase of the study, $15 \mathrm{EFL}$ teachers were selected based on their cluster membership. From these 15 participants, nine teachers were male, and six teachers were female. Also, 12 teachers held the bachelor's degree, and three teachers held the master's degree.

Instrument: Semi-structured Interviews - In the qualitative phase, an in-depth semi-structured interview was carried out to detect what factors shape the EFL teachers' motivational profiles for teaching, and to gain information about the reasons EFL teachers have for teaching as their profession. The participants responded to open-ended questions and statements which were designed by the researchers based on the components of the MTQ. In order to increase the reliability and validity, the data from the interview were analyzed by two raters who were experienced EFL instructors. Furthermore, the correlation between each of the two possible pairings of rating assigned by the two raters indicated 0.89 inter-rater reliability. The participants were asked to answer questions like as following: "What do you think of teaching (English)?", "How do you feel teaching helps you?", "Is it important to you what others think about you as a teacher?", and "Are you obliged to teach by others (colleagues, school principals)?" The interviews took about 30 minutes in average, and were audio recorded.

\section{Procedures and data analysis}

This study employed a mixed method sequential explanatory design in order to answer the research questions. Because of the fact that neither qualitative nor quantitative methods are sufficient by their own to provide a detailed information about participants' motivational factors both kinds of data were mixed in this study. As stated by some researchers, when we use both quantitative and qualitative methods in combination, they complement each other; and therefore, the analysis will become more robust and precise (Tashakkori \& Teddlie, 1998). The method consisted of two distinct phases: the quantitative phase and the follow-up qualitative phase (Creswell, 2013). In this design, first the quantitative data were collected and analyzed. Second, the qualitative data were collected and analyzed in order to help explain, or elaborate on, the quantitative results obtained in the first phase (Ivankova, Creswell, \& Stick, 2006).

In the quantitative phase both variable- and person-centered approaches were adopted. Most previous studies (e.g., Fortunato \& Goldblatt, 2006; Vansteenkiste, Sierens, Soenens, Luyckx, \& Lens, 2009) have approached teacher motivation using a variable-centered approach. Although the variable-centered approach has provided important insights in relation to the role of motivational regulations in teachers' functioning, it has typically studied autonomous and controlled motivation separately without focusing on their dynamic interaction. As stated by Ntoumanis (2002), one distinctive attribute of the works on motivation is that the different motivational types and their contributing factors in isolation are examined. This might be quite questionable since the assumption that a person with high levels of intrinsic motivation should have low levels of extrinsic motivation ignores the multidimensional characteristic of motivation (Vallerand \& Fortier, 1998); while all types of motivation can be present within an individual to different degrees (Deci \& Ryan, 1991; Vallerand \& Fortier, 1998).

However, some teachers may have a combination of different motivations to engage in their job, so that they 
engage in their job because of both external demands proposed by their job and their inherent desire and passion to teach (Van den Berghe et al., 2013). The advantage of a person-centered approach with cluster analyses is that it makes it possible to identify naturally occurring combinations of teachers' reasons to teach which constitute different motivational profiles.

Therefore, in the present study, apart from adopting a variable-centered approach, a person centered approach (i.e., cluster analysis) was adopted to investigate how different types of motivation combine within one individual EFL teacher and are characterized by a particular motivational profile. For this purpose, first, all of the participants, selected through convenience sampling, were informed about the aim of the study. This nonprobability sampling technique was used because of the convenient accessibility and proximity of the participants to the researchers. Then, the participants asked to provide their demographic information and complete the MTQ questionnaire they received through an e-mail containing a brief description of the study or as hard copies delivered by hand.

The quantitative data analysis was conducted using SPSS (version 23.0). Initially, adopting a variable-centered approach, descriptive statistics, Cronbach's alpha for MTQ, and correlation coefficients were calculated to understand the major types of motivation of EFL teachers and their interrelationships. Subsequently, through a person-centered approach, a two-stage cluster analysis procedure was used (Gore, 2000; Hair, Anderson, Tatham, \& Black, 1998) to identify the motivational profiles of EFL teacher. To examine the differences among the three clusters on the four types of motivation a one-way multivariate analysis of variance (MANOVA) was used with a follow-up univariate analysis (ANOVA) and post-hoc Tukey comparison tests. Finally, in order to examine the associations between demographic variables and three motivational clusters, Chi-square tests were conducted.

In the qualitative phase, 15 teachers with different motivational profiles were selected to be interviewed. An in-depth semi-structured interview was conducted face-to-face or over the phone with each participant for approximately 30 minutes. The analysis of the qualitative data collected through the interviews was carried out by using a structured process described by Creswell (2013). First, the interviews were recorded and transcribed. Significant statements and key words that described the sources of participants' motivation to teach were coded as free nodes as suggested by Creswell (2013). Then, the identified significant statements were assigned to the themes and then into final categories. Finally, the sources of individuals' motivations within clusters were illuminated and described.

\section{Findings and discussion}

\subsection{The quantitative phase}

First, internal reliabilities for each of the MTQ subscales were calculated using standardized Cronbach's alpha coefficients. The reliability of MTQ in this study was satisfactory $(\alpha=.80)$. The MTQ also indicated appropriate internal consistency with all subscales ranging from .70 to .79 except for introjected regulation subscale $(\alpha=.60)$, which was a little low. However, because it was an essential component of SDT and above .50, it was kept for the remaining analyses. Second, to find the answer of the first research question of the study, all variables data were subjected to descriptive statistics computed in the form of mean $(M)$, standard deviation $(S D)$, as well as intercorrelations among the intended variables by using pearson product-moment correlation coefficents. Table 1 shows the descriptive statistics of all the MTQ subscales.

Among the four motivational variables, identified regulation and intrinsic motivation obtained the highest mean score, $(M=16.79, M=16.67$ respectively), and external regulation gained the lowest mean score $(M=10.87)$. This indicated that the EFL teachers in the present study were highly self-determined in their teaching engagement. 
An investigation into EFL teachers' motivation to teach from a self-determination perspective

Table 1

Descriptive statistics for $M T Q$

\begin{tabular}{lccccc}
\hline \multicolumn{1}{c}{ Variables } & N of items & Min & Max & M & SD \\
\hline Intrinsic motivation & 4 & 4 & 20 & 16.67 & 3.05 \\
Identified regulation & 4 & 6 & 20 & 16.79 & 2.956 \\
Introjected regulation & 4 & 4 & 20 & 11.73 & 3.88 \\
External regulation & 4 & 4 & 20 & 10.87 & 3.47 \\
\hline
\end{tabular}

Correlational statistics between motivation and demographic variables demonstrated that motivation subscales were differentially related to demographic variables. Intrinsic motivation and identified regulation had significant and positive correlations with gender variable, they also had positive, but nonsignificant, associations with employment status. These two types of autonomous motivation had negative associations with age, educational degree, years of experience, and place of work. On the other hand, there were positive correlations between introjected regulation and educational degree and employment status. There was also negative association between external regulation and educational degree. Table 2 summarizes the correlations results between motivation types and demographic variables.

Table 2

Correlations between the study variables

\begin{tabular}{lcccccc}
\hline \multicolumn{1}{c}{ Variables } & Gender & Age & $\begin{array}{c}\text { Educational } \\
\text { degree }\end{array}$ & $\begin{array}{c}\text { Years of } \\
\text { experience }\end{array}$ & $\begin{array}{c}\text { Place of } \\
\text { work }\end{array}$ & Emplyment status \\
\hline Intrinsic motivation & $.189 *$ & -.097 & -.091 & -.149 & -.036 & .084 \\
& $(.044)$ & $(.302)$ & $(.333)$ & $(.111)$ & $(.699)$ & $(.371)$ \\
Identified regulation & $.194 *$ & -.044 & -.035 & -.148 & -.014 & .086 \\
& $(.038)$ & $(.644)$ & $(.711)$ & $(.114)$ & $(.886)$ & $(.363)$ \\
Itrojected regulation & -.025 & -.121 & .143 & -.049 & -.061 & .067 \\
& $(.787)$ & $(.198)$ & $(.127)$ & $(.604)$ & $(.520)$ & $(.478)$ \\
External regulation & .131 & .076 & -.062 & .028 & .021 & .059 \\
& $(.162)$ & $(.419)$ & $(.509)$ & $(.770)$ & $(.828)$ & $(.532)$ \\
\hline Note. $* p<.05$ & & & & & &
\end{tabular}

The second research question was intended to determine Iranian EFL teachers' motivational clusters on the basis of their scores for four types of motivation (intrinsic motivation, identified, introjected, and external regulations). In line with past research using cluster analyses in education and sport (e.g., Gillet, Vallerand, \& Rosnet, 2009), it was hypothesized that three motivational profiles would be identified using cluster analysis. Three clusters were expected to emerge: (1) a cluster characterized by moderate to high scores on autonomous motivation (intrinsic motvation and identified regulation) and low scores on controlled motivation (introjected regulation and external regulation); (2) a cluster characterized by moderate scores on both autonomous and controlled motivations; and (3) a cluster characterized by high scores on both autonomous and controlled motivations.

In order to assign individuals into clusters and identify motivational profiles, scores on four types of motivation were included in a hierarchical cluster analysis using Ward's method of linkage with the squared Euclidian distance measure. Ward's method (see Milligan \& Cooper,1987) was used in this study to minimize the variance within clusters. This analysis is sensitive to outliers; thus, two multivariate outliers for the motivational variables were excluded because they had high Mahalanobis distance values. Afterwards, a non-hirarchical $\mathrm{k}$-means cluster analysis was performed to specifiy a three cluster solution and to confirm the initial cluster centers resulting from the hierarchical cluster analysis. Based on psychometric evidence (e.g., means, standard deviation, $p$ values), the three-cluster solution was considered to fit the data best. Means and standard deviations of the motivation subscales for the three groups are reported in Table 3. 
Roohani, A., Hashemian, M., \& Dayeri, K.

Table 3

Descriptive statistics for the three-cluster solution

\begin{tabular}{|c|c|c|c|c|c|c|c|c|c|c|c|c|}
\hline \multirow[t]{2}{*}{ Variables } & \multicolumn{2}{|c|}{$\begin{array}{c}\text { Cluster } 1 \\
\text { "Moderate" } \\
(n=45)\end{array}$} & \multicolumn{2}{|c|}{$\begin{array}{l}\text { Cluster } 2 \\
\text { "High" } \\
(n=59) \\
\end{array}$} & \multicolumn{2}{|c|}{$\begin{array}{l}\text { Cluster } 3 \\
\text { "Low" } \\
(n=11) \\
\end{array}$} & \multirow[t]{2}{*}{$F$} & \multirow[t]{2}{*}{$p$} & \multirow[t]{2}{*}{$\eta^{2}$} & \multirow[b]{2}{*}{$\begin{array}{c}\text { C1 vs. } \\
\text { C2 }\end{array}$} & \multirow[b]{2}{*}{$\begin{array}{c}\text { C1 vs. } \\
\text { C3 }\end{array}$} & \multirow[b]{2}{*}{$\begin{array}{c}\text { C2 vs } \\
\text { C3 }\end{array}$} \\
\hline & M & SD & M & $\mathrm{SD}$ & M & $\mathrm{SD}$ & & & & & & \\
\hline $\begin{array}{l}\text { Intrinsic } \\
\text { motivation }\end{array}$ & 17.42 & 1.88 & 17.30 & 2.29 & 10.27 & 3.05 & 49.79 & .000 & .47 & .12 & $7.14 *$ & $7.03 *$ \\
\hline $\begin{array}{l}\text { Identified } \\
\text { regulation }\end{array}$ & 17.71 & 1.67 & 17.28 & 2.16 & 16.79 & 2.95 & 57.96 & .000 & .50 & .42 & $7.35^{*}$ & $6.93 *$ \\
\hline $\begin{array}{l}\text { Introjected } \\
\text { regulation }\end{array}$ & 8.44 & 2.11 & 14.84 & 1.95 & 11.73 & 3.88 & 121.74 & .000 & .68 & $-6.40 *$ & -.01 & $6.39 *$ \\
\hline $\begin{array}{l}\text { External } \\
\text { regulation }\end{array}$ & 10.31 & 3.42 & 12.01 & 3.07 & 10.87 & 3.47 & 12.33 & .000 & .18 & $-1.70 *$ & 3.22 & 4.92 \\
\hline
\end{tabular}

Figure 1. Motivational profiles identified by cluster analysis

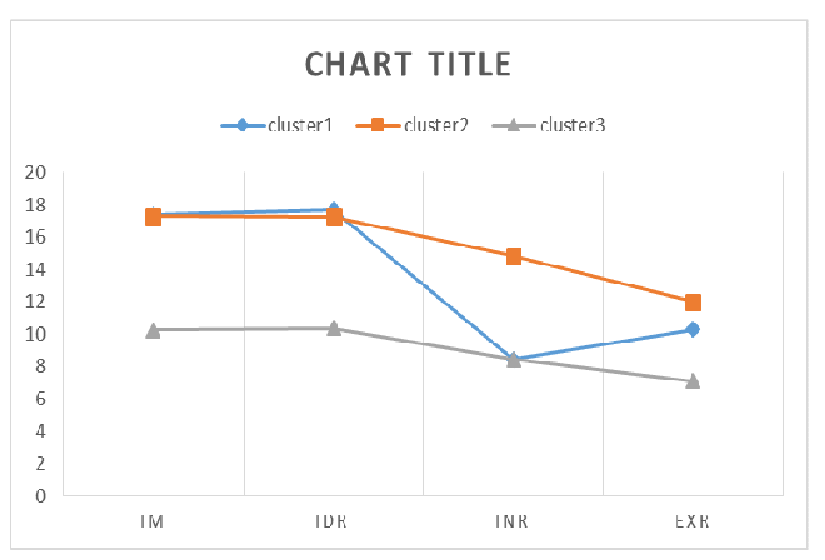

The first cluster included $40 \%$ of the sample $(n=45)$ and was labeled the Moderate group. This cluster included EFL teachers whose motivational profile was characterized by moderate to high levels of autonomous motivation, and moderate levels of controlled motivation. The second cluster was labeled the High group and represented $51 \%$ of the sample $(n=59)$. Teachers in this cluster showed high levels of autonomous and controlled motivation. Finally, the participants in the third cluster represented $9 \%$ of the sample $(n=11)$ and included teachers who displayed moderate levels of autonomous motivation and low levels of controlled motivation. Thus, this cluster was labeled the Low group. As Figure 1 indicates, the Moderate group (cluster 1) and the High group (cluster 2) shared quite the same levels of autonomous motivation which is caracterized by intrinsic motivarion and identified regulation; nevertheles, with regard to controlled motivation, the introjected regulation differentiates the two groups from one another.

To examine whether differences existed among the three clusters on the four forms of motivation, a MANOVA was conducted. Results revealed significant differences between the three clusters on the four motivational constructs, $F(8,218)=45.206, p=.000$. The follow up univariate analyses with post-hoc Tukey were conducted to identify where significant differences lied. Univariate $F$ values showed a significant effect of cluster membership on each type of motivation. Detailed results of these univariate analyses as well as clusters' size and means are shown in Table 3. The results of post-hoc comparison revealed that the three Low, Moderate, and High groups were significantly different from each other $(p<.05)$ on these four motivational subscales.

In order to assess the third question of the study which was to explore the potential relation of demographic variables with EFL teachers' motivation, Chi-square analyses were conducted. Cluster membership was selected as the dependent variable and demographic varaibles as independent variables. The result indicated significant relationships between cluster membership and EFL teachers' demographic characteristics for years of experience 
An investigation into EFL teachers' motivation to teach from a self-determination perspective $(p=.020)$ and place of work $(p=.020)$. Table 4 shows the Chi-square statistics.

\section{Table 4}

The comparison of the three clusters in terms of demographic characteristics

\begin{tabular}{llllllll}
\hline \multicolumn{1}{c}{ Clusters/Demographics } & Cluster 1 & Cluster 2 & Cluster 3 & Total & $\boldsymbol{\chi}^{2}$ & $\boldsymbol{p}$ \\
\hline Gender & Male & 7.8 & 16.5 & 5.2 & 26.6 & 5.47 & .06 \\
& Female & 31.3 & 34.8 & 4.3 & 70.4 & & \\
\hline Age & $21-25$ & 1.7 & 2.6 & .00 & 4.3 & 8.46 & .58 \\
& $26-30$ & 11.3 & 16.5 & 1.7 & 29.6 & & \\
& $31-35$ & 8.7 & 12.2 & 1.7 & 22.6 & & \\
& $36-40$ & 6.1 & 6.1 & 3.5 & 17.7 & & \\
& $41-45$ & 11.3 & 12.2 & 1.7 & 25.2 & & \\
\hline Educational degree & BA and over & .00 & 1.7 & .9 & 2.6 & & \\
& MA & 27.0 & 29.6 & 6.1 & 62.6 & 1.72 & .78 \\
& PhD & 11.3 & 20.0 & 3.5 & 34.8 & & \\
\hline Years of & $5-10$ & .9 & 1.7 & .00 & 2.6 & & \\
experience & $11-15$ & 18.3 & 31.3 & 1.7 & 1.7 & 20.42 & $.020^{*}$ \\
& $16-20$ & 7.0 & 3.5 & 1.7 & 12.2 & & \\
& $21-25$ & 6.1 & 3.5 & 2.6 & 12.2 & & \\
& $26-30$ & 6.1 & 9.6 & 1.7 & 17.4 & & \\
\hline Place of work & Junior high school & 7.8 & 14.8 & .9 & 23.5 & 11.25 & $.020^{*}$ \\
& High school & 12.2 & 8.7 & 6.1 & 27 & & \\
\hline Employment status & Full-time & 20.9 & 24.3 & 7.0 & 52.2 & 2.41 & .29 \\
& Part-time & 18.3 & 27 & 2.6 & 47.8 & & \\
\hline
\end{tabular}

\subsection{The qualitative phase}

In the process of quantitative data analysis, the main types of EFL teachers' motivation and their motivational clusters were identified through variable- and person-centered approach. The qualitative data analysis was conducted to answer the last research question in order to illustrate the factors and sources of FFL teachers' motivations within each cluster. Qualitative results from the interviews are presented below. Overall, the interview data confirmed the results of statistical procedures in the quantitative phase and revealed several factors characterizing the EFL teachers' motivational profiles.

Narrative description of cluster 1 - In support of the quantitative findings, the results from the interview revealed that the cluster 1 (Moderate group) was mainly characterized by the high levels of intrinsic reasons (i.e., enjoyment for teaching) and identified regulation (i.e., considering teaching as an important life goal) which showed these participants were autonomously motivated to engage in their teaching profession. Besides, they reported low levels of introjected and external regulations for teaching which demonstrated that their reasons to teach were not controlled. These teachers expressed enthusiasm and passion toward teaching in general and EFL teaching, in particular. Interview with members of this group revealed some reasons for teaching English including interest into English language itself, learning and experiencing new things through language teaching, and the possibility of communication with the world. Therefore, we can imply that usefulness and effectiveness is one factor which led to participants' commitment in EFL teaching profession.

One of the teachers, who worked in institutes for five years, said,

I am interested in teaching English because I can learn many things from other cultures and communicate with their people.

He also perceived teaching more holistically and mentioned, 
Roohani, A., Hashemian, M., \& Dayeri, K.

In human service jobs like teaching, we can have positive influences on people's life and also on our own personal life... I consider teaching as a valuable job career.

Another participant, with seven years of experience in both schools and institutes, said that her enthusiasm for teaching rooted in high school when she selected teaching as her important life choice. She also put emphasis on the positive effects of teaching on his personal characteristics and added,

I have become more sociable and self-confident through teaching. Mm...It is valuable for me because I have learned to be more patient and punctual.

Overall, the participants in Cluster 1 reflected excitement and dedication to their teaching profession, a desire to help students to learn an L2 language, and an awareness of their key role as educators in the society. Another teacher, with five years of experience, in response to the question "Is teaching valuable for you?" asserted,

Yes, it is valuable because making people learn and understand another language in Iran where English is considered as a foreign language can be a valuable attempt... mm...at least as a teacher you are a part of this learning.

Moreover, the participants in this cluster believed that external factors did not affect their motivation to teach. In line with this view, one teacher, with eight years of teaching experience in institutes, said:

Well...it is not important for me what others think about my teaching; everyone has its own idea about teaching language. For example, some of my students and colleagues think that putting students in stress lead them to understanding and learning, but some of them do not.

Another teacher, with six years of experience in institutes, emphasized, "I am not obliged to teach by others. I like it and nobody forces me in this respect." In sum, they reported that external expectations and demands were not influential in their job effectiveness and commitment. It seems they had come to this profession with values about teaching and learning English and desire to positively affect other people.

Narrative description of cluster 2 - Cluster 2 was considered as the High group because teachers in this cluster showed high levels of both autonomous and controlled motivation. The participants in this cluster were similar in many ways to participants in cluster 1, especially in their autonomous reasons for teaching. The two groups shared the same motives for teaching (usefulness and effectiveness). Like participants from Moderate group, teachers in the High group considered teaching as a valuable profession which brings them many worthwhile accomplishments. One of the participants with this motivational profile, with six years of experience in both schools and institutes, described teaching this way:

I do not consider teaching as a job, it is a precious attempt to influence people's life... um... it is so valuable for me.

One factor which was highlighted in their interviews was the social respect people have towards teaching career, and this might be a trigger for teachers to put more effort on this job. As stated by a teacher in this cluster, who taught for ten years in schools, "Students and their families have specific respect for the teachers. It doesn't really happen for other jobs." In the same token, cluster 2 interviewees viewed the teachers as those on whom people, including families and students can rely and trust. To them, people are tended to consult with teachers about different issues and problems they face because they have always found teachers as guides and advisors.

One specific characteristic which makes the High group distinctive from the Moderate group is that they have external regulations for teaching, as well. It appears that the others' views and expectations about the way they teach is important to them, so the external regulations seems to be a substantial factor in their commitment to their job. When they were asked: "Is it important to you what others think about your teaching?", they mostly confirmed 
An investigation into EFL teachers' motivation to teach from a self-determination perspective

it was important to them, and argued that it could be influential in their teaching. The rationale behind their views was described by one of them below:

It is important what others think about my teaching. Giving the teacher some encouragement will motivate him/her to find different ways in order to express him/herself and make it public, but when some people discourage or do not praise you, you think that you are doing something in vein without a purpose.

Another teacher, with 12 years of experience in schools, viewed the school principal and other teachers' views to be effective for her teaching development. She expressed "If to others' view my teaching has problems; I try to solve that problem to progress in my teaching." EFL teachers in this motivational cluster confirmed that they feel guilty if they do not teach and become disappointed since they expect themselves to teach. They also admitted the external expectations such as organizational demands had a strong role in their teaching commitment. One of the EFL teachers, who taught for 11 years at schools, emphasized that

When you accept to teach, it is your responsibility to make an effort in your career. You do not have the right to be carefree towards students learning.

Teachers with High motivational profile also put emphasis on the psychological aspects of this profession which can influence both students and teachers' progress. As an example of this view, one teacher mentioned,

As you deal with people through your job, it can help you how to communicate with other people and how to understand their emotions, and to be patient.

He continued,

Teaching is a kind of life; you have to live with it....mm...how to tackle problems in the class is like just to tackle the problems in real life.

In their point of view, teachers' psychological demands must be taken into account in order to increase teachers' quality. This is in line with the need to satisfy the psychological human needs, particularly autonomy as proposed by Deci and Ryan (2000). According to them, in order to feel autonomous, individuals need to have the capability to have their own choices and experiences, and the interview data analysis confirmed this assumption. The members of this group underscored the need for giving space and opportunities to teachers to communicate their thoughts and viewpoints regarding teaching methodologies. Therefore, having the choice in the teaching process can be considered as one of potential factors in teachers' enthusiasm for the job. Furthermore, cluster 2 participants viewed the increased workload as having a detrimental effect on their motives to teach. One of the teachers in this group believed that

Teaching should be accompanied by some other jobs ... and it should be considered as an activity in which individuals feel relaxed when they teach.

Another one explained:

If they want me to have different classes with many work hours, ... um ... I would refuse to work because I want to be fresh when I enter the class. I want to be an effective teacher not a mentally and physically tired one who cannot transmit the knowledge to her students."

In essence, the data gathered through interviews revealed that EFL teachers identified by Cluster 2 were similar with cluster 1 teachers in their inherent and intrinsic initiatives and their deriving force to teach. However, cluster 2 was distinct in that all members of this group demonstrated a high level of controlled motivations as well as autonomous motivations for teaching and seemed to be influenced by external forces and expectations.

Narrative description of cluster 3 - Compared to the participants in the other two clusters, the participants in 
Roohani, A., Hashemian, M., \& Dayeri, K.

cluster 3 which was labeled as Low group showed the moderate levels of autonomous motivation and low levels of controlled motivation in their interviews. The EFL teachers with this motivational profile did not express a high interest in teaching. Although they seemed not to be influenced by external forces to engage in teaching and had entered the profession with enthusiasm, they expressed moderate levels of motivation at the moment. Some participants with this motivational profile indicated that there were some work-related factors which negatively influenced their motivation and job satisfaction; and if they had a chance, they would look for better job opportunities. One of these factors which they mentioned in their interviews was the negative impact of the educational system in the schools. One participant, who taught in a high school for more than seven years, explained,

At the beginning, it was really pleasant, but day by day, I felt I was doing the routine stuff, and there was no creativity...even if I had some creativity, the administration and education system did not allow me to use my creative thoughts ... the time did not allow me ....the students were not motivated enough, and their parents did not care about these things. So, I felt like disappointed after six or seven years of teaching.

The low group expressed the sense of insecurity and dissatisfaction when dealing with school administrators and even with students, and had a feeling of inefficacy as a result of the unappealing educational system. They also believed that whether they teach in school or in the institute could affect the EFL teachers' motivation to teach which was in accordance with the results of quantitative data analysis. According to them, in the school, teachers deal with variety of students with different internal and external orientations, and some individual differences force the teacher "to make some choices, and making this choices will sacrifice some of the students and give some privilege to some others.", as one of them pointed it out. The cluster 3 participant actually considered students' motivation as a source of difference between the two work environments. Another interviewee with nine years of experience in both schools and institutes, who was a member of this cluster, elaborated on the issue:

In institutes, students come to class to learn things and the teacher just has to decide what strategies and styles to take to teach them...mm...He doesn't care about the motivation factor a lot ..., so I think the students' motivation is the key factor.

One teacher who taught in school for 17 years criticized the current system of teaching English in schools and asserted:

I don't agree with the way we teach English now. We actually demotivate students not motivate them. Because the current methods of EFL teaching are based on the grammar and written exams. Oral evaluations are not that important. We should provide them a relaxed atmosphere .... Fortunately, it is going to change.

Another work-related factor that the majority of the EFL teachers in cluster 3 agreed on was the possibility of making decisions and having the choices in institutes. This is the point that cluster 2 members also mentioned. As clarified by one participant, with six years of experience in schools and institutes,

You can make decisions how to teach because there is no force, there is no compulsion and, you have to just find the best way to teach, but at school the most important factor is finishing the book.

Another teacher, with 16 years of experience in schools added:

I chose teaching with love, I am not regretful now. But I'm not as motivated as I was before. I wouldn't have selected it definitely with this condition.... Once, one of my student told me he wanted to be a teacher and asked my advice. And, I told him it's not a good idea at all because teaching needs passion and love. 
An investigation into EFL teachers' motivation to teach from a self-determination perspective

One important factor which demotivated teachers to continue their profession was the financial aspect of teaching. There was a general consensus among all teachers in cluster 3 that the EFL teaching is not a well-paid job, and there is not a balance between the workload and the payment. Therefore, they gradually become demotivated and lose their commitment to their job. One of the EFL teachers, with 15 years of experience, expressed his dissatisfaction this way,

They pay us peanuts really...mm... When you feel you are not well-paid, and you could have chosen something which is well-paid, you will keep asking yourself what stupid mistake I have ever done.

In general, unlike the other two clusters, participants in cluster 3 demonstrated the job-related demands and problems EFL teacher have to deal with. They did not talk much about their innate desire for teaching. They mostly said that their driving force to become a teacher was not their passion about teaching. All in all, cluster 3 teachers' motivational profile was characterized by low levels of intrinsic and identified regulation resulting from the conflict between the participants' inherent desire to teach and the real work-related expectations and educational demands and policies they have encountered.

The main objective of the present study was to identify the EFL teachers' motivational profiles and to examine the relationship between these profiles and demographic variables through a mixed method approach. The quantitative findings indicated that the autonomous types of motivation including intrinsic motivation and identified regulation were the most prominent types of motivation among EFL teachers in this study. The results also uncovered the existence of three clusters: The Low, Moderate, and High groups. The highest percentage belonged to the High group and the lowest percentage belonged to the Low group. Different combinations of reasons were found to be related to each group's choice of teaching English as a career, but at the same time, some common sources of motivation were recognized across the three groups. This result can be in line with Deci and Ryan's (2000) who have an opposite view regarding dichotomous nature of different types of motivation (i.e., intrinsic vs. extrinsic). Thus, alongside with the variable-centered approach, the person-centered investigation showed that the majority of EFL teachers participated in this study were autonomously motivated to their teaching commitment. The findings of the present study are align with current findings in the literature regarding the predominance of intrinsic reasons for teaching as powerful motivators (e.g., Pop \& Turner, 2009; Thomson et al., 2012).

In addition, the findings of this study revealed that some demographic characteristics of the participants were related to their motivational profiles; therefore, the idea that teachers' profiles are merely based on different types of motivation to teach regardless of demographic characteristics is ruled out. Significant differences among cluster membership and such variables as years of experience and place of work were found. It seems it makes a difference for EFL teachers whether they teach in a private institute or in a school. The rules governed in the two educational environment seem to influence their motivations to teach. This indicates the influential role of work-related conditions in enhancing or weakening EFL teachers' motivation and desire for teaching. Moreover, the above results indicate that the number of teaching years can impact their commitments and enthusiasm to teach. In a sense, this finding is in contrast to the findings of some other studies (e.g., Richardson \& Watt, 2005; Watt \& Richardson, 2008) which have shown that demographic characteristics had no role in shaping teachers' motivational clusters.

The follow-up qualitative analysis from the interviews revealed the underlying sources of EFL teachers' motivational profiles in more depth. The interview data showed that teachers might have a combination of both intrinsic and extrinsic reasons to engage in their jobs. The qualitative analysis also revealed that different psychological and job-related issues might impact teachers' intrinsic motivations for teaching as the result of discrepancy between the teachers' psychological needs and the real organizational pressures and demands. The EFL teachers with high autonomous motivation indicated that the usefulness and effectiveness of the job and the inherent nature of English language, which would open the doors to the new world, were the sources of their 
desire to be an EFL teacher. On the other hand, the participants with low autonomous motivation, considered some multifaceted job-related issues as the causes of their dissatisfaction and detachment from their job. In light of the above issues, it can be argued that the educational policies, and monetary issues might be the major sources of EFL teachers' frustration and disappointment. The qualitative data also confirmed the impact of some demographic variables, including the place of work and years of experience. The results showed that the EFL teachers who worked in the schools belonged to the Low group having moderate to low levels of autonomous motivation, and were mostly experienced with at least 15 years of teaching English.

\section{Conclusion}

This study made use of a mixed method investigation to provide a picture of EFL teachers' motivational status. It explored the types of motivation EFL teachers had towards their job and uncovered the role of different psychological and organizational factors on their motivation for teaching. The results of both quantitative and qualitative investigation showed that the majority of participants of the present study were autonomously motivated in their job commitment. The participants with high autonomous motivations expressed the sense of joy and intrinsic desire to engage in their teaching career. Some participants had a combination of both autonomous and controlled motivations. Although they had some inherent reasons for their teaching, they could not deny the role of external factors forcing them to continue their job. The EFL teachers with low levels of intrinsic motivation did not have the same view about teaching as the other groups had. In general, the participants of the present research indicated that some psychological and job-related factors such as the students' motivation, the capability of the choice and making decisions, the workload, and specifically financial issues could be considered as factors having some side effects on teachers' motivation and progress.

Findings from the present study have implications not just for understanding different types of EFL teachers' motivation for engaging in teaching profession, but eventually understanding the sources of factors intervowen with EFL teachers' commitment to teaching, job satisfaction, and possibly their attrition. Beside on the above findings, teacher education programs and policy makers in the era of EFL teaching and teacher education can reflect on the importance of recognizing the different motivational types of EFL teachers and views about the teaching/learning. School principals and policy makers in L2 educational settings can also take different job-related factors into account when they design their policies and set their organizational goals and demands in order to help EFL teachers function in a more useful way. In addition, by using a person-centered approach accompanied by a variable-centered approach, this study showed how complex EFL teachers' motivations could be, contrary to previous research (e.g., Benedetti, Diefendorff, \& Chandler, 2015; Lam \& Gurland, 2008), which simplified the picture and simply reported differences in motivations for career choice.

Cluster analytic approach in this study illuminated the quality of the EFL teachers' motivation within each profile. The motivational clusters identified in this study may shed new lights to communicating with EFL teachers in a way that is more professional and fruitful than the typical view on motivation. It might be necessary to take different approaches to encourage the EFL teachers with different motivational profile in order to be need-supportive and open to constructive pieces of advice. This understanding of teachers motivational types would be beneficial not only for the EFL teachers' personal functioning but also for the improvement of the teacher-student interaction and learning.

This study was the first attempt to adopt a person-centered approach regarding EFL teachers' motivation and investigated only the nature and the sources of motivational profiles. Further research can be implemented to explore the relations of these profiles to teaching and learning performances, outcomes, and accomplishments in EFL teachers. Future research using longitudinal designs can examine which groups of EFL teachers are more liable to stay or leave the profession. Such research could provide insights contributing to EFL teacher education programs, work-related factors of the teaching profession, or both. Additionally, some other psychological factors such as teachers' characteristics and their pedagogical knowledge could be investigated with respect to identified motivational profiles and their relationship with EFL teachers' attrition. 


\section{References}

Benedetti, A. A., Diefendorff, J. M., Gabriel, A. S., \& Chandler, M. M. (2015). The effects of intrinsic and extrinsic sources of motivation on well-being depend on time of day: The moderating effects of workday accumulation. Journal of Vocational Behavior, 88, 38-46. https://doi.org/10.1016/j.jvb.2015.02.009

Bieg, S., Backes, S., \& Mittag, W. (2011). The role of intrinsic motivation for teaching, teachers' care and autonomy support in students' self-determined motivation. Journal for Educational Research Online, 3(1), 122-140.

Creswell, J. W. (2013). Research design: Qualitative, quantitative, and mixed methods approaches (3rd ed.). Thousand Oaks, CA: Sage.

Deci, E. L. (1971). Effects of contingent and non-contingent rewards and controls on intrinsic motivation. Organizational Behavior and Human Performance, 8, 217-229. https://doi.org/10.1016/0030-5073(72)90047-5

Deci, E. L. (2009). Large-scale school reform as viewed from the self-determination theory perspective. Theory and Research in Education, 7(2), 244-252. https://doi.org/10.1177/1477878509104329

Deci, E. L., \& Ryan, R. M. (1985). Intrinsic motivation and self-determination in human behavior. New York, NY: Plenum. https://doi.org/10.1007/978-1-4899-2271-7

Deci, E. L., \& Ryan, R. M. (1991). A motivational approach to self: Integration in personality. In R. Deinstbier (Ed.), Nebraska symposium on motivation (pp. 237-288). Lincoln, NE: University of Nebraska Press.

Deci, E. L., \& Ryan, R. M. (2000). The "what" and "why” of goal pursuits: Human needs and the self-determination of behavior. Psychological Inquiry, 11, 227-268. https://doi.org/10.1207/S15327965PLI1104_01

Deci, E. L., \& Ryan, R. M. (2002). Handbook of self-determination research. New York: The University of Rochester Press.

Deci, E. L., Vallerand, R. J., Pelletier, L. G., \& Ryan, R. M. (1991). Motivation in education: The self-determination perspective. The Educational Psychologist, 26, 325-346. https://doi.org/10.1080/00461520.1991.9653137

Dörnyei, Z., \& Ushioda, E. (2011). Teaching and researching motivation. Pearson Education Limited.

Fortunato, V. J., \& Goldblatt, A. M. (2006). An examination of goal orientation profiles using cluster analysis and their relationships with dispositional characteristics and motivational response patterns. Journal of Applied Social Psychology, 36, 2150-2183. https://doi.org/10.1111/j.0021-9029.2006.00099.x

Gillet, N., Berjot, S., Vallerand, R. J., Amoura, S., \& Rosnet, E. (2012). Examining the motivation-performance relationship in competitive sport: A cluster-analytic approach. International Journal of Sport Psychology, 43, 79-102. https://doi.org/10.1007/s11031-008-9115-Z

Gillet, N., Vallerand, R. J., \& Rosne, E. (2009). Motivational clusters and performance in a real-life setting. Motivation and Emotion, 33, 49-62.

Gore, P. A. (2000). Cluster analysis. In H. Tinsley \& S. Brown (Eds.), Handbook of applied multivariate statistics and mathematical modeling (pp. 298-321). San Diego: Academic Press. https://doi.org/10.1016/B978-012691360-6/50012-4

Griva, E., Panitsidou, E. A., \& Chostelidou, D. (2012). Identifying factors of job motivation and satisfaction of foreign language teachers. Procedia, Social and Behavioral Sciences, 46, 543-547.

https://doi.org/10.1016/j.sbspro.2012.05.157

Hair, J. F., Anderson, R. E., Tatham, R. L., \& Black, W. C. (1998). Multivariate data analysis. Upper Saddle River: Prentice Hall.

Hidi, S., \& Harackiewicz, J. M. (2000). Motivating the academically unmotivated: A critical issue for the 21 st century. Review of Educational Research, 70, 151-179. https://doi.org/10.3102/00346543070002151

Ivankova, N. V., Creswell, J. W., \& Stick. S. L. (2006). Using mixed-methods sequential explanatory design: From theory to practice. Field Methods, 18(1), 3-20. https://doi.org/10.1177/1525822X05282260

Kumazawa, M. (2013). Gaps too large: Four novice EFL teachers' self-concept and motivation. Teaching and Teacher Education, 33, 45-55. https://doi.org/10.1016/j.tate.2013.02.005

Lam, C. F., \& Gurland, S. T. (2008). Self-determined work motivation predicts job outcomes, but what predicts self-determined work motivation? Journal of Research in Personality, 42, 1109-1115. https://doi.org/10.1016/j.jrp.2008.02.002

Milligan, G. W., \& Cooper, M. C. (1987). Methodology review: Clustering methods. Applied Psychological Measurement, 11, 329-354. https://doi.org/10.1177/014662168701100401 
Roohani, A., Hashemian, M., \& Dayeri, K.

Nieto, S. (2005). Why we teach. Columbia University, NY: Teachers College Press.

Ntoumanis, N. (2002). Motivational clusters in a sample of British physical education classes. Psychology of Sport and Exercise, 3, 177-194. https://doi.org/10.1016/S1469-0292(01)00020-6

Pelletier, L., Seguin-Levesque, C., Legault, L. (2002). Pressure from above and pressure from below as determinants of teachers' motivation and teaching behaviors. Journal of Educational Psychology, 94, 186-196. https://doi.org/10.1037/0022-0663.94.1.186

Poonam, D. C. (1997). Intrinsic motivation and academic achievement. Remedial and Special Education, 18(1), 12-20. https://doi.org/10.1177/074193259701800104

Pop, M. M., \& Turner, J. E. (2009). The organizational socialization process of second-career teachers: A heuristic inquiry (Unpublished Doctoral dissertation), Gonzaga University.

Reeve, J., Bolt, E., \& Cai, Y. (1999). Autonomy-supportive teachers: How they teach and motivate students. Journal of Educational Psychology, 9, 537-548. https://doi.org/10.1037/0022-0663.91.3.537

Richardson, P. W., \& Watt, H. M. G. (2005). I've decided to become a teacher' influences on career change. Teaching and Teacher Education, 21, 475-489. https://doi.org/10.1016/j.tate.2005.03.007

Sandres, W. L., (2000). Value-added assessment from student achievement data: Opportunities and hurdles. Journal of Personnel Evaluation in Education, 14(4), 329-339. https://doi.org/10.1023/A:1013008006096

Soenens, B., Sierens, E., Vansteenkiste, M., Dochy, F., \& Goossens, L. (2012). Psychologically controlling teaching: Examining outcomes, antecedents, and mediators. Journal of Educational Psychology, 104, 108-120. https://doi.org/10.1037/a0025742

Tashakkori, A., \& C. Teddlie, C. (1998). Mixed methodology: Combining qualitative and quantitative approaches. Applied Social Research Methods Series, vol. 46. Thousand Oaks, CA: Sage.

Thomson, M. M., Turner, J. E., \& Nietfeld, J. L. (2012). A typological approach to investigate the teaching career decision: Motivations and beliefs about teaching of prospective teacher candidates. Teaching and Teacher Education, 28, 324-335. https://doi.org/10.1016/j.tate.2011.10.007

Vallerand, R. J., \& Fortier, M. S. (1998). Measures of intrinsic and extrinsic motivation in sport and physical activity: A review and critique. In J. L. Duda (Ed.), Advances in sport and exercise psychology measurement (pp. 81-101). Morgantown, WV: Fitness Information Technology.

Van den Berghe, L., Bart Soenens, B., Aelterman, N., Cardon, G., Tallir, I. B., \& Haerens, L. (2014). Within-person profiles of teachers' motivation to teach: Associations with need satisfaction at work, need-supportive teaching, and burnout. Psychology of Sport and Exercise, 15, 407-417. https://doi.org/10.1016/j.psychsport.2014.04.001

Van den Broeck, A., Vansteenkiste, M., De Witte, H., Soenens, B., \& Lens, W. (2010). Capturing autonomy, competence, and relatedness at work: Construction and initial validation of the work-related basic need satisfaction scale.

Journal of Occupational and Organizational Psychology, 83, 981-1002. https://doi.org/10.1348/096317909X481382

Vansteenkiste, M., Soenens, B., Sierens, E., Luyckx, K., \& Lens, W. (2009). Motivational profiles from a self-determination perspective: The quality of motivation matters. Journal of Educational Psychology, 101(3), 671-688. https://doi.org/10.1037/a0015083

Watt, H. M. G., \& Richardson, P. W. (2008). Motivations, perceptions, and aspirations concerning teaching as a career for different types of beginning teachers. Learning and Instruction, 18, 408-428. https://doi.org/10.1016/j.learninstruc.2008.06.002

Watt, H. M. G., \& Richardson, P. W. (2011). Teachers' profiles of professional engagement and career development in Australia and the U.S. Paper presented at the European Association for Research on Learning and Instruction (EARLI) International Conference, Exeter, UK.

Weiner, B. (1985). An attributional theory of achievement motivation and emotion. Psychological Review, 92(4), 548-573. https://doi.org/10.1037/0033-295X.92.4.548 